\title{
Impact of Grid Strength on HVDC Connection Requirements
}

\author{
Tibin Joseph, Carlos Ugalde Loo, Gen Li \\ and Jun Liang \\ School of Engineering, Cardiff University \\ Cardiff, Wales, UK \\ \{JosephT, Ugalde-LooC, LiG9, LiangJ1\}@cardiff.ac.uk
}

\author{
Oluwole D. Adeuyi, M. H. Rahman and Ian Cowan \\ The National HVDC Centre, \\ Cumbernauld, Glasgow, UK. \\ \{Oluwole.Adeuyi, Md.Rahman, Ian.L.Cowan2\}@sse.com
}

\begin{abstract}
AC Grid Codes are well documented and constantly being updated by industry and electricity system operators. However, the deployment of power electronics-based technology into conventional ac power systems brings significant challenges for system operators. As high-voltage direct-current (HVDC) technologies keep developing, the existence of hybrid ac and dc systems may be standard in future power grids. Although HVDC brings flexibility to the system, the control strategies have become more complex. In addition, stability issues brought by a reduced system inertia resulting from the gradual replacement of synchronous machines with HVDC-connected generation are becoming very important-particularly when connected to weak ac grids. Therefore, the compliance of conventional Grid Codes should be settled urgently to tackle operational challenges. In this paper, Grid Code requirements on HVDC schemes connected to weak grids are presented. Reactive power and fault ride-through requirements specified by the European Network Code and the Great Britain Grid Code on HVDC are analyzed in detail. The impact of grid strength on the operational requirements of HVDC systems connected to weak grids and compliance testing are performed through simulation studies conducted on a test system.
\end{abstract}

Index Terms-Grid Code, High-voltage direct-current, ShortCircuit Ratio, Weak Grids

\section{INTRODUCTION}

Several new high-voltage direct-current (HVDC) connections (e.g. embedded HVDC links, HVDC interconnectors and HVDC systems for the grid integration of offshore wind farms) are expected in the Great Britain (GB) network by 2030. The successful integration of HVDC schemes into the existing ac grid will play a critical role in developing a sustainable and resilient GB power system. By 2025 , the operation of the GB electricity transmission network is expected to be completely coal-free and, to meet these targets, HVDC schemes will play an important role [1]-[3].

Grid Codes including both ac and dc grid specifications are under constant revision in order to reflect appropriate requirements for electricity networks [6]-[7], [9]. For instance, the GB electricity system regulator constantly reviews existing Grid Codes related to power systems operations, with input from multiple stakeholders [9].

Most of the existing Grid Codes assume that HVDC connections are made to strong ac grids and the guidelines for weak connections are limited [5]-[7]. This constitutes an important issue demanding attention given the reduced grid strength at different locations of the GB network, where multiple in-feed HVDC links either exist or are planned (e.g. in South-Eastern England and Northern Scotland) [6], [11]. It is expected that the total HVDC installed capacity in GB could double to $16 \mathrm{GW}$ by 2027 - up from $8 \mathrm{GW}$ of existing capacity in 2019 [4]. A key requirement for HVDC schemes will be the provision of active power control and frequency support. This has been highlighted, together with other general specifications, in ENTSO-E's Network Code (NC) on grid integration of HVDC [7]. This is also highlighted in the GB Grid Code, where the main emphasis is placed on frequency management, inertia and short-circuit in-feed, fault ridethrough (FRT) requirements and voltage regulation [8].

GB has 7 different HVDC schemes in operation and additional projects are planned-comprising interconnections to grids from other countries and embedded links for onshore network reinforcement (see Fig. 1) [4]-[5]. The replacement of conventional synchronous generation with HVDC-connected renewable energy sources will reduce the GB system strength (represented as short-circuit ratio, SCR). The GB's electricity system operator National Grid (NGESO) has identified this scenario and found that a considerable amount of decline in SCR is foreseen in the GB network by 2025 , which has to be incorporated in the existing Grid Code provisions [4]-[5]. To this end, stringent or limited operating conditions could be imposed on HVDC connections at weak areas or regions with declining SCR. Inadequate Grid Code requirements may cause reliability or stability issues; however, too onerous requirements can prevent reaching energy policy targets.

Connection of HVDC schemes to ac grids and Grid Code compliance tests have been widely examined in the literature [11]-[18]. The compliance of voltage source converter (VSC) based HVDC schemes to FRT requirements has been reported in [11]-[13]. A recent EU project developed open-access models for Grid Code compliance tests of HVDC and de grids [14], [15]. Articles on the frequency support requirements from HVDC converters were presented in [16]-[18]. Subsynchronous interactions and damping provision using HVDC technologies to comply with Grid Codes are also an area of research interest [19]-[20]. However, a strong ac system is assumed in most cases - both in the literature and in the existing Grid Codes. The declining SCR and, thereby, the strength of the ac grid where the HVDC terminals are connected, is not considered. This will be of importance in future networks with the potential for low system strength and, thus, requires immediate attention. To address this situation, it would be beneficial for system operators to specify appropriate control responses for HVDC schemes connecting to areas with relatively weak network strengths.

To address the aforementioned issues, this paper reviews the key specifications and requirements of existing Grid Codes for HVDC schemes in GB and in Europe. In addition, a test 
system with an embedded VSC-HVDC link connected to a weak ac system is employed to analyze the impact of grid strength on Grid Code connection requirements - in particular, with respect to reactive power and FRT requirements.

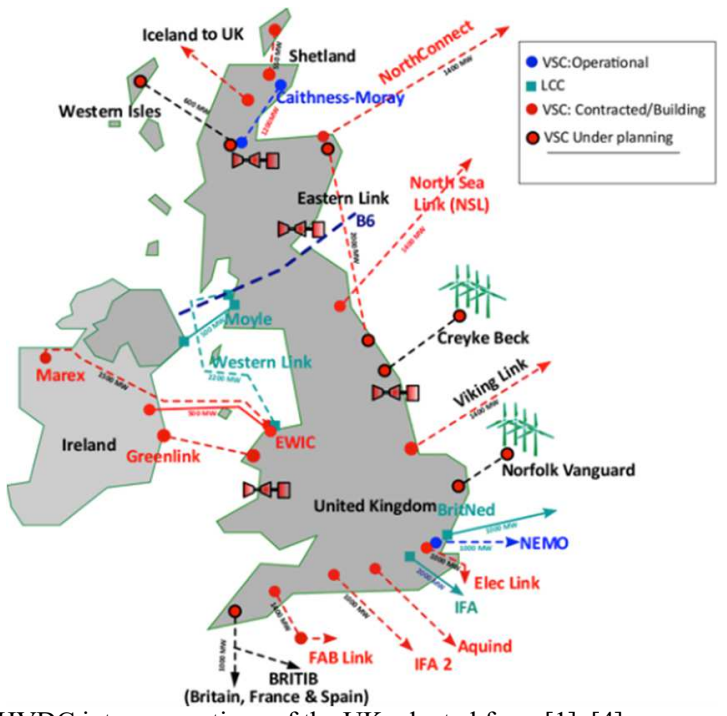

Fig.1. HVDC interconnections of the UK adapted from [1], [4].

\section{GRID STRENGTH AND SHORT CIRCUIT RATIO}

Within the context of HVDC connections to an ac grid, the well-documented and accepted measure for system strength (or weakness) is the SCR. However, numerous indices are used to quantify grid strength. In general, SCR can be defined as the ratio between short-circuit capacity $\left(S C C_{M V A}\right)$ from a threephase line-to-ground fault at a given location in the power system and the rating of the inverter- based resource connected to that location [21]-[24]:

$$
S C R=\frac{S C C_{M V A}}{S_{d c}}
$$

where $S C C_{M V A}$ is the short-circuit capacity in MVA of the ac system including HVDC and $P_{d c}$ is the MW rating of the dc link. It is assumed that sufficient strength at the specific busbar is obtained when the SCR is at least equal to 3 [23], [24]. This requires knowledge of the short-circuit capacity $S C C_{M V A}$, which is calculated using the IEC 6090 standard, used for grid planning purposes, defined by [23]:

$$
S C C_{M V A}=\sqrt{3} U_{L L} I_{s c}
$$

where $U_{L L}$ is the nominal line-to-line voltage at the point of common coupling (PCC) and $I_{s c}$ is the three-phase short circuit current, defined in turn by.

$$
I_{s c}=\frac{U_{L L}}{\sqrt{3} Z_{s c}}
$$

where $Z_{s c}$ is the Thevenin equivalent short-circuit impedance seen from the PCC. SCR can be written in terms of impedance as

$$
S C R=\frac{U_{L L}^{2}}{S_{d c}} \cdot \frac{1}{Z_{s c}} .
$$

It can be observed from (4) that SCR is a function of the short-circuit impedance and is sensitive to the operating conditions in the network. The minimum value of SCR with a rated dc power transmission level must be considered when analyzing the limiting operating conditions and Grid Code requirements.

\section{TEST SYSTEM: EMBEDDED VSC- HVDC LINK}

To evaluate the impact of grid strength on HVDC connections and its compliance with existing Grid Code requirements, a test system considering an embedded VSCHVDC link is adopted. This has been modeled using PSCAD.

\section{A. Test system Configuration}

The system under study is shown in Fig. 2, which is configured to represent an embedded VSC-HVDC link in the North of Scotland. This HVDC scheme transfers up to 800 $\mathrm{MW}$ of additional renewable generation capacity from MMC1 to MMC2. The VSC-HVDC link model implemented in PSCAD is based on a half-bridge modular multi-level converter (MMC) technology considering generic control loops. It transmits power through a $113 \mathrm{~km}$ subsea cable between the converter stations. Generation at Grid 1 is dominated by onshore wind. Considering that the typical system strengths at the PCC of industrial HVDC connections can vary from 1 to 5 GVA [25], such an SCR range will be considered at Grid 1.

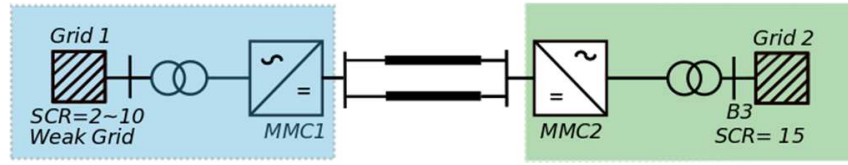

Fig. 2. Embedded VSC-HVDC link configuration.

Fig. 3 illustrates the three-phase configuration, with the high-level control scheme of the MMC station being shown in Fig. 4. The control scheme is based on a cascaded structure in a $d q$ reference frame: an outer loop regulates power or dc voltage and an inner loop regulates current [19], [20]. The $d$-axis reference current is designed either to regulate active power or the dc voltage of the MMC. The $q$-axis reference current is designed either to regulate reactive power or the ac voltage of the MMC. More specifically, MMC1 is equipped with an active power and reactive power control mode, while MMC2 regulates dc voltage and reactive power and operates as a slack bus during normal operation.

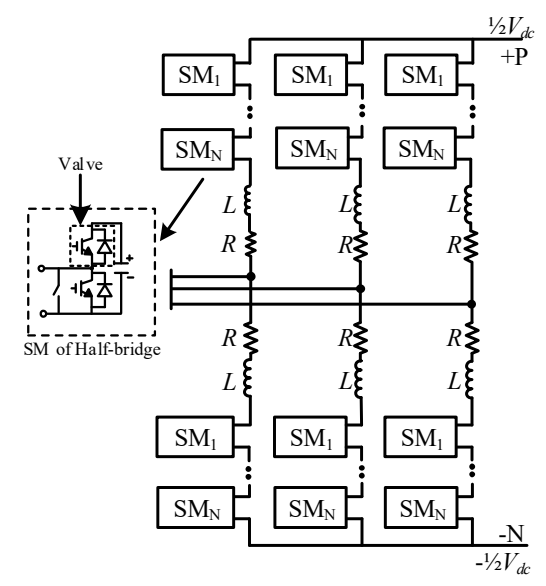

Fig. 3. MMC Configuration. 


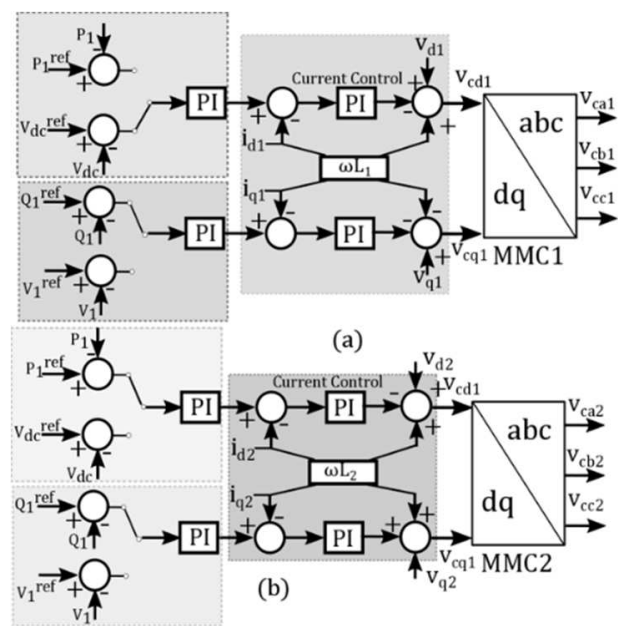

Fig. 4. Control hierarchy of HVDC link: (a) MMC1; (b) MMC2.

\section{B. Grid Code Requirements for HVDC connections}

These demand HVDC connections to contribute to voltage regulation in the system - as conventional power plants do particularly when the grid is weak. Moreover, the technical specification and operation of HVDC under grid disturbances or faults and post-fault operation is of great significance given the potential scenario of a declining system strength. To serve this purpose, the Network Code (NC) on HVDC Connections from ENTSO-E sets out clear and specific requirements for HVDC system owners, which is also reflected in the GB Grid Codes managed by NGESO [7]-[8]. These two families of codes were compared in terms of reactive power and FRT requirements to identify synergies for weak grid operation.

\section{1) Reactive power Requirements}

Reactive power requirements (RPRs) are usually expressed with $P-Q$ diagrams (available active power versus available reactive power). Different RPRs are summarized in Fig. 5, where specifications from different countries are considered. In general, at full active power, the converter must be capable of supplying reactive power in the range 0.41 p.u. inductive to 0.48 p.u. capacitive, which corresponds to a power factor from 0.925 lagging to 0.9 leading [7]. The GB Grid Code demands that HVDC connections and dc connected power plants to be able to provide 0.95 lagging to 0.9 leading reactive power support [8]. The specific requirements for voltage and reactive power regulation are summarized in Table I for both the NC HVDC and the GB Grid Code.

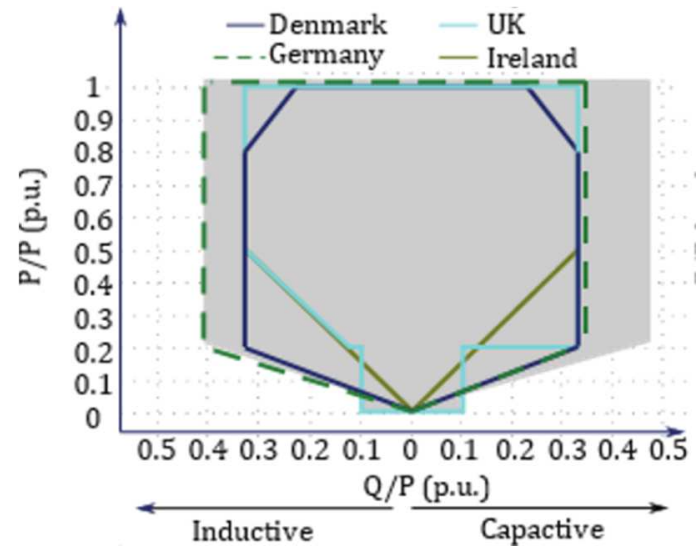

Fig. 5. Reactive power requirements of various Grid Codes.
TABLE I. REACTIVE POWER REQUIREMENTS FOR NC HVDC AND

\begin{tabular}{|c|c|c|c|c|c|}
\hline \multicolumn{3}{|c|}{ Voltage parameters (p.u.) } & \multicolumn{2}{c|}{ Time parameters (seconds) } \\
\hline Term & NC & NGESO & Term & NC & NGESO \\
\hline $\mathrm{U}_{\text {ret }}$ & $0-0.3$ & 0 & $\mathrm{t}_{\text {ret }}$ & $0.14-0.25$ & 0.14 \\
\hline $\mathrm{U}_{\text {clear }}$ & $\mathrm{n} / \mathrm{a}$ & 0 & $\mathrm{t}_{\text {clear }}$ & $\mathrm{n} / \mathrm{a}$ & 0.14 \\
\hline $\mathrm{U}_{\text {rec1 }}$ & $0.25-0.85$ & 0 & $\mathrm{t}_{\text {rec1 }}$ & $1.5-2.5$ & 0.14 \\
\hline $\mathrm{U}_{\text {rec } 2}$ & $0.85-0.9$ & 0.85 & $\mathrm{t}_{\text {rec2 } 2}$ & $\mathrm{t}_{\text {rec1 }}-10$ & 2.2 \\
\hline
\end{tabular}

TABLE II. FRT REQUIREMENTS FOR EUROPEAN NC HVDC

\begin{tabular}{|c|c|c|}
\hline Mode & NC HVDC & NGESO \\
\hline Power Factor & 0.95 lead -0.95 lag & 0.95 lead -0.95 lag \\
\hline Voltage Range & $\begin{array}{c}1.1 \text { p.u. }-0.875 \text { p.u. } \\
(0.225 \text { p.u. })\end{array}$ & $\begin{array}{c}1.1 \text { p.u. }-0.875 \text { p.u. } \\
\text { (0.225 p.u.) }\end{array}$ \\
\hline $\begin{array}{c}\text { Maximum } \\
\text { Q/Pmax }\end{array}$ & 0.95 & 0.95 \\
\hline
\end{tabular}

2) Fault Ride-Through Requirements

An HVDC system shall fulfil voltage stability requirements as specified in the relevant Grid Codes and be capable of providing active and reactive support for the ac system. Also, the HVDC system shall have FRT capability. Therefore, HVDC system owners should ensure that the operation and control of their HVDC system is able to meet all the Network Code [7].

Fig. 6 shows the FRT requirement (critical fault clearance time) of an HVDC converter for a user system entry point of an HVDC interface at or above $110 \mathrm{kV}$, as defined in the European NC [7]. The diagram represents the lower limit of a voltage-against-time profile at the connection point, expressed by the ratio of its actual value and the reference value (1 p.u.) before, during, and after a fault.

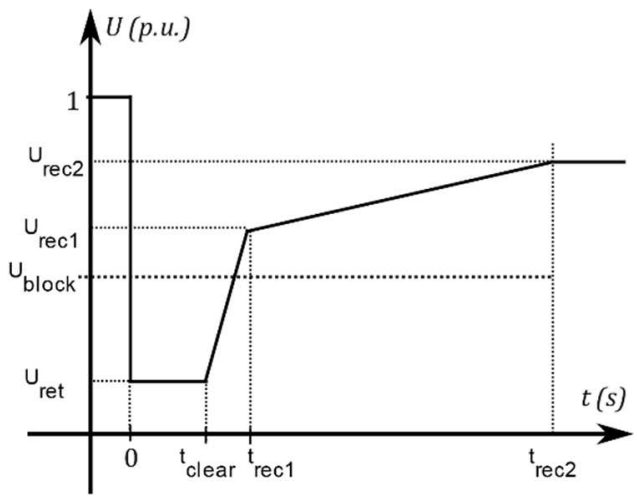

Fig. 6. FRT profile of an HVDC converter station (European NC).

In Fig. 6, $\mathrm{U}_{\text {ret }}$ is the retained voltage at the connection point during a fault, $t_{\text {clear }}$ is the instant when the fault has been cleared, and $\mathrm{U}_{\mathrm{recl}}$ and $\mathrm{t}_{\mathrm{rec} 1}$ specify a point of lower limits of voltage recovery following fault clearance. Ublock is the blocking voltage at the connection point. The time values referred to are measured from tfault. The parameters and time scale are presented in Table II for the FRT requirements specified in the European NC and by NGESO [7]-[8].

For the GB Grid Code, it should be noted that the pre-fault voltage shall be taken to be 1.0 p.u. and the post-fault voltage shall not be less than 0.9 p.u. This is depicted in Fig. 7 [8]. 


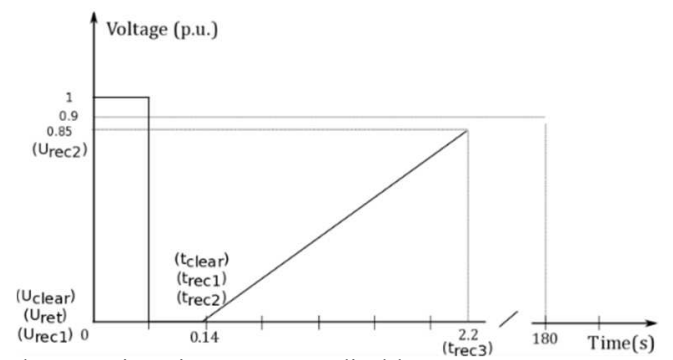

Fig. 7. Voltage-against-time curve applicable to HVDC systems and remote end HVDC converter stations (GB Grid Code).

\section{Simulation Results}

To study the performance of the HVDC link and its Grid Code compliance in a weak grid condition, the embedded HVDC link (see Fig. 2) has been implemented in PSCAD. Detailed switching MMC models with 40 submodules per arm are used together with their associated control systems. DC cables are represented by frequency dependent models. The ac grids at the ends of the HVDC link are modeled appropriately to represent different grid strengths. Unless stated otherwise, the simulations are started with Grid 1 operating as a strong system, with the value of SCR being reduced at $t=0.5 \mathrm{~s}$ into the simulation.

\section{A. Reactive Power Requirements for P-Q Control (Mode 1)}

The ability of the converter connected to a weak grid to meet the RPRs shown in Fig. 5 is examined. The operation is performed at Grid 1. At $t=1 \mathrm{~s}$ into the simulation, the power factor is changed from 0.95 (lead) to 0.95 (lag) and the process is reversed at $t=2 \mathrm{~s}$. Two cases are assessed for comparison, with system operating condition and control modes detailed in Table III. The active/reactive power $(P-Q)$ control mode is used for MMC1, while MMC2 operates in dc voltage/reactive power control. The cases are given as follows:

- Case-1: Step change in reactive power set point from $\square 200$ to 200 MVAr.

- Case-2: Ramp change in reactive power set point from $\square$ 200 to 200 MVAr with a $200 \mathrm{~ms}$ ramping period.

\begin{tabular}{|c|c|c|}
\multicolumn{1}{c|}{ TABLE III. CONTROL MODES FOR SIMULATION STUDIES } \\
\hline \multirow{3}{*}{ Mode } & Control Mode 1 & Control Mode 2 \\
\hline \multirow{3}{*}{$\mathrm{MMC} 1$} & $P$ and $Q$ & $P$ and $V_{a c}$ with $4 \% Q$ droop \\
\cline { 2 - 3 } & $P=800 \mathrm{MW} ;$ & $P=800 \mathrm{MW} ; V_{a c}=275 \mathrm{kV} ;$ \\
& $Q=200 \mathrm{MVAr}$ & $Q=200 \mathrm{MVAr}$ \\
\hline \multirow{2}{*}{$\mathrm{MMC} 2$} & \multicolumn{2}{|c|}{$V_{d c}-Q$} \\
\cline { 2 - 3 } & \multicolumn{2}{|c|}{$V_{d c}=640 \mathrm{kV}( \pm 320 \mathrm{kV}) ; Q=200 \mathrm{MVAr}$} \\
\hline
\end{tabular}

As it can be observed in Fig. 8, for Case 1, the converter is capable of delivering the rated power within the specified range without any difficulties when the grid is sufficiently strong. However, the power flow through the HVDC link is compromised with reduced values of SCR. The voltage at the PCC exhibits marginal stability at $\mathrm{SCR}=3$ and becomes unstable for low values of SCR (see Fig. 8(c)).

Simulation results for Case 2 are shown in Fig. 9. As it can be observed, when reactive power is ramped up, voltage stability can be preserved for SCR $=3$ as opposed to Case 1 . Instability is also reflected in the active and reactive power responses. It can be inferred that a stable voltage at the converter terminal is required to maintain phase-locked loop
(PLL) synchronism. Voltage changes are directly linked to system strength and require consideration in the Grid Code so as to maintain system stability and security under weak grid operation.
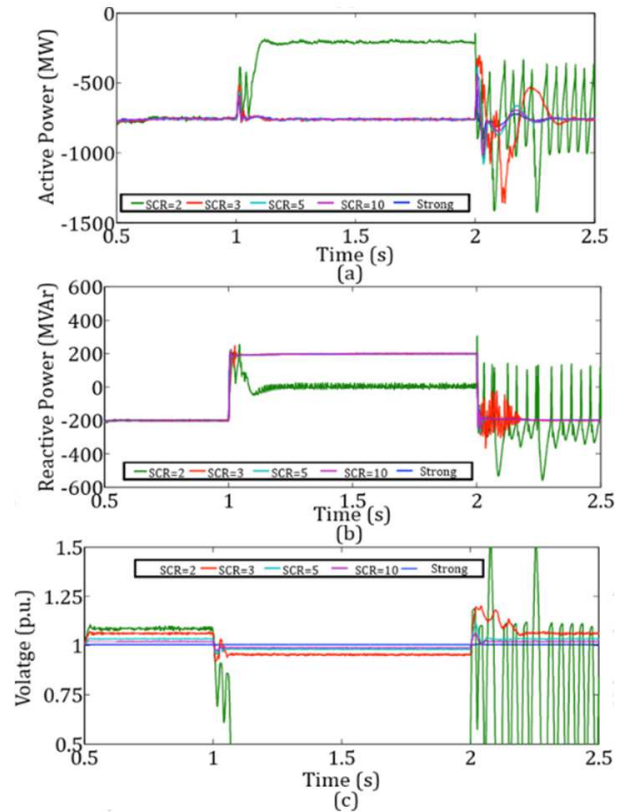

Fig. 8. Case 1. System performance for a range of SCRs upon a step change in reactive power set point: (a) active power; (b) reactive power; (c) PCC voltage.

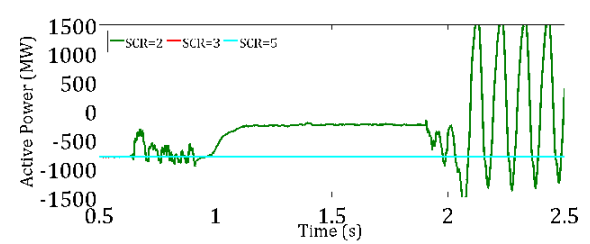

(a)

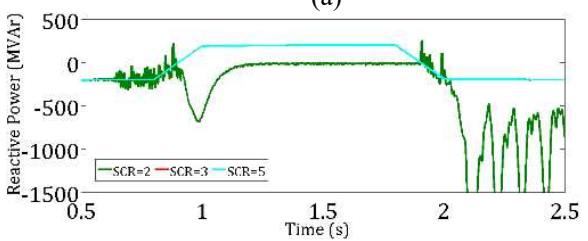

(b)

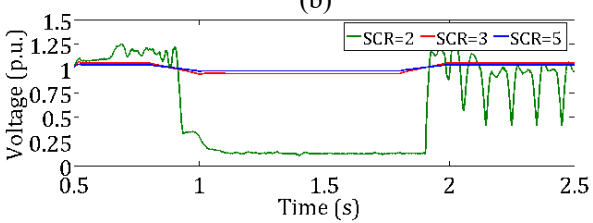

(c)

Fig. 9. Case 2. System performance for a range of SCRs upon a ramped change in reactive power set point: (a) Active power; (b) reactive power; (c) PCC voltage.

B. Reactive Power Requirements for P-(Vac v.s. Q) Droop Control (Mode 2)

A study is performed to investigate the performance of the HVDC link for different SCRs and a $P$ - $\left(V_{a c}\right.$ vs. $\left.Q\right)$ droop control mode. Details of the test system and operating modes are outlined in Table III. MMC1 is controlled in a $P$ - $\left(V_{a c}\right.$ vs. $\left.Q\right)$ droop control mode to assess reactive power compliance.

The SCR value of Grid 1 is reduced at $t=0.5 \mathrm{~s}$ into the simulation to both identify a stable operating condition and to 
assess Grid Code compliance. The active power response follows its reference down to values of SCR $=3$, but is unstable for $\mathrm{SCR}=2$, as shown in Fig. 10. However, for a reduced power injection of 0.5 p.u., a stable operation with $\mathrm{SCR}=2$ is possible (see blue trace in Fig. 10). This condition with a reduced power flow shows that, compared to the $P-Q$ control mode, the $P-\left(V_{a c}\right.$ v.s. $\left.Q\right)$ droop control mode may offer stability for lower SCR values. Such an enhanced performance could be attributed to the direct control of the ac voltage at the PCC to maintain a constant value. This, in turn, results in a stable PLL operation and therefore stable power flow.

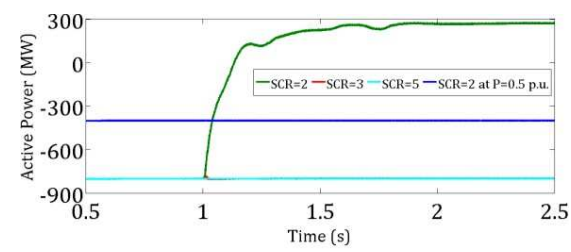

(a)

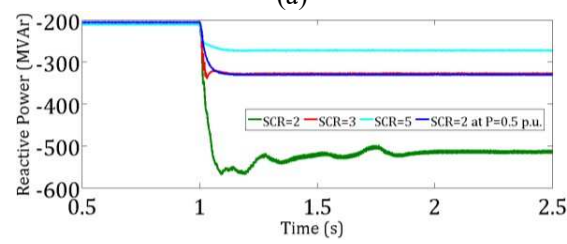

(b)

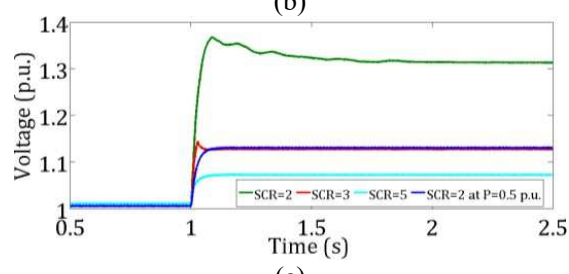

(c)

Fig. 10. System performance for a range of SCRs for ac voltage control mode of MMC1. A reduced power injection for $\mathrm{SCR}=2$ is assessed as well. (a) Active power; (b) reactive power; (c) PCC voltage.

\section{Case Study for FRT Requirements}

The HVDC performance during FRT and compliance with to NC HVDC and NGESO Grid Codes were investigated using the following case studies

- Case 1: FRT test. Three-phase symmetrical fault applied at Grid 1 for 140 ms, with MMC1 in Control Mode 1;

- Case 2: FRT test. Three-phase symmetrical fault applied at Grid 1 for 140 ms, with MMC1 in Control Mode 2.

In this study, the SCR value of Grid 1 in changed from 10 to a different value at $t=0.7 \mathrm{~s}$ to emulate a weak grid. This operation causes oscillations for $\mathrm{SCR}=2$, as seen in Figs. 11 and 12. For Case 1, the active and reactive power responses shown in Fig. 11 reflect a stable operation until SCR $=3$. However, voltage instability might occur for higher values of SCR ( $>3)$, across severe faults, different operating conditions, different HVDC control gains, or different PLL settings (not shown). Such aspects require further investigation.

Fig. 12 demonstrates FRT compliance against requirements ECC.6.3.15 detailed in ECP.A.3.5 and ECP.A.6.7 of the GB Grid Code for Case 1 [8]. The post-fault profile is above the solid black line for $\mathrm{SCR}=5$. In this case, $\mathrm{HVDC}$ systems or dc connected power park modules must remain connected and stable. However, if the post-fault voltage dips below the solid black line, as seen for SCR $=2$, the HVDC system is permitted to trip. On the other hand, it is important to note that for $\mathrm{SCR}=$ 3 , the post-fault voltage does not cross the requirement curve but is unstable - causing potential unforeseen technical difficulties to operate the HVDC systems and dc connected modules. This aspect also requires further investigation.

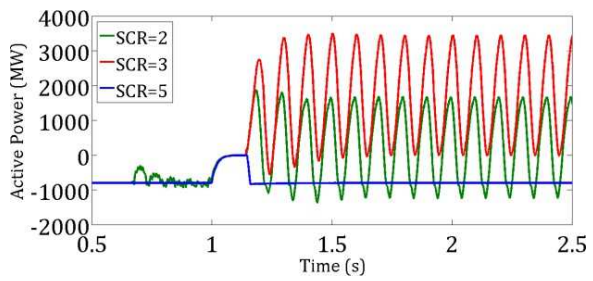

(a)

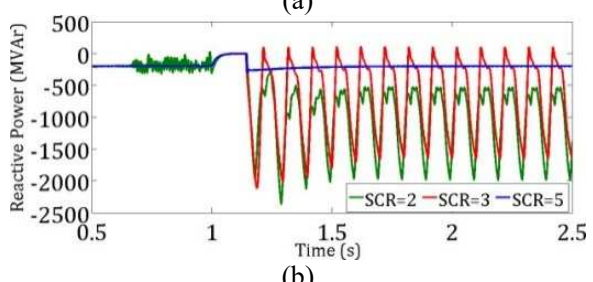

(b)

Fig. 11. FRT requirements with Control Mode 1 at MMC1: (a) Active power; (b) reactive power.

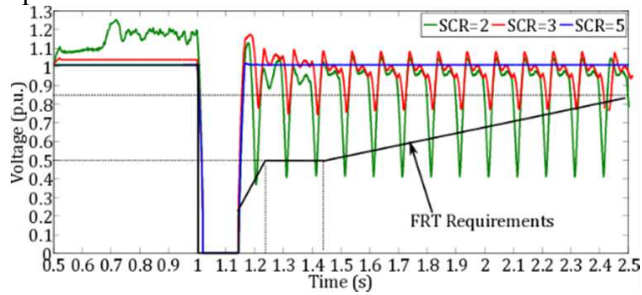

Fig. 12. Voltage response for the FRT requirement for Case 1.

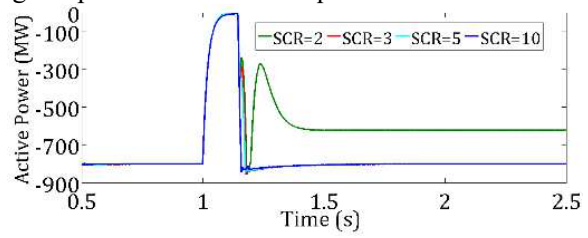

(a)

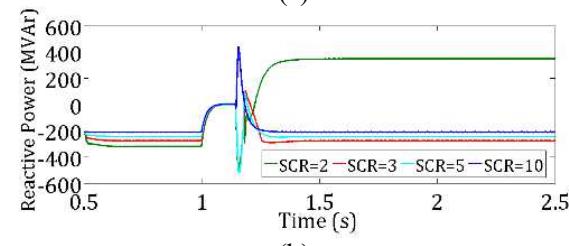

(b)

Fig. 13. System performance for FRT requirement for Case 2. (a) Active power; (b) reactive power.

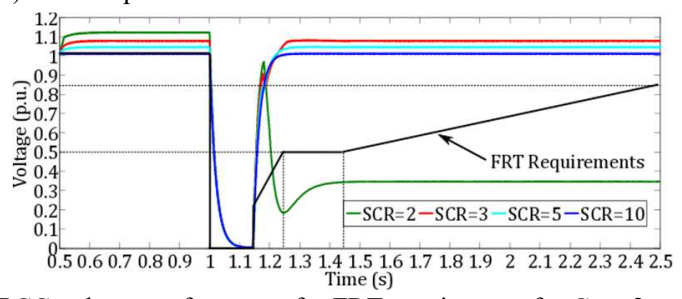

Fig. 14. PCC voltage performance for FRT requirement for Case 2.

For Case 2, the active and reactive power responses shown in Fig. 13 reflect stable operation until $\mathrm{SCR}=3$. When compared to Case 1, voltage instability does not occur for a severe fault in this control mode, afforded by the constant regulation of ac voltage at the connection point of the converter-as discussed in Section IV-B. 
On the other hand, for a $P-V_{a c}$ control mode, as shown in Fig. 14, the FRT compliance against requirements of ECC.6.3.15 detailed in ECP.A.3.5 and ECP.A.6.7 of the GB Grid Code is met for an $\mathrm{SCR}=3$. For $\mathrm{SCR}=2$, the post-fault voltage dips below the solid black line. In this case, the HVDC system is permitted to trip. However, the operation is compromised due to the weak grid characteristics. The postfault voltage profile recovers upon fault clearance and is well within the requirement for SCR values until 3.

\section{DISCUSSION AND FUTURE WORK}

From the review of two Grid Codes and the case studies conducted in this paper, it has been found that the GB Grid Code does not make any allowances for different SCR at the PCC when HVDC connections are considered. Results obtained through PSCAD-based simulations of an embedded HVDC link connected to a weak system show the impact that changes in SCR may have on the system operating condition and compliance with the existing GB Grid Code. The necessity for relaxing or tightening the connection requirements should be considered by system operators not only at planning and commissioning stages, but also across the lifetime of the project.

On the other hand, as shown in the case studies, the converter controllers used for HVDC systems play a vital role in the compliance of connection requirements. However, detailed information on control parameters is protected by propriety rights and is, therefore, not accessible for tuning during operational periods. This could be a barrier for implementing a simple method to improve the operation of HVDC systems connected to weak grids. Alternative methods will be investigated in the future to ensure safe and stable HVDC connections to existing ac grids where SCR may vary.

\section{CONCLUSIONS}

Following a review exercise of the Grid Codes by European NC HVDC and NGESO for HVDC schemes, it can be concluded that a considerable level of flexibility is provided for national TSOs compared to those in continental Europesuch as the specification of reactive power and FRT requirements. However, there are also common grounds for operation modes to potentially harmonize both Grid Codes. For instance, these include minimum requirements for voltage regulation at steady-state and post-fault operation. With regards to technical requirements, it can be concluded from the study conducted on an embedded HVDC link that the HVDC converters connected to a weak ac grid with an ac voltage control perform better than when a reactive power control mode is in place. This was also found to be true for steady-state and fault conditions. Hence, other control schemes, such as ac voltage vs. reactive power droop control, could merit further investigation.

An important conclusion arising from the studies performed in this paper is that the necessary requirements for voltage regulation and pre-fault and post-fault recovery are in place for the HVDC connection to relatively strong grids. ENTSO-E is considering the inclusion of services like synthetic inertia and fast fault current injection into their $\mathrm{NC}$ HVDC requirements for HVDC schemes connected to a weak grid. However, these specifications have not been yet fully explored and incorporated in the GB Grid Code and, thus, require additional attention.

\section{REFERENCES}

[1] T. Joseph, "Operation and control of voltage source converters in transmission networks for AC system stability enhancement," $P h D$ thesis, Cardiff University, Mar. 2018.

[2] T. Joseph, C. E. Ugalde-Loo, J. Liang and P. F. Coventry, "Asset Management Strategies for Power Electronic Converters in Transmission Networks: Application to Hvdc and FACTS Devices," IEEE Access, vol. 6, pp. 21084-21102, April 2018.

[3] G. Li, J. Liang, F. Ma, C. E. Ugalde-Loo and H. Liang, "Analysis of Single-Phase-to-Ground Faults at the Valve-Side of HB-MMCs in HVDC Systems," IEEE Trans. Ind. Electron., vol. 66, no. 3, pp. 24442453, March 2019.

[4] S. Marshall, CM Project stake holder engagement event, National HVDC Centre, March 2019.

[5] S. Marshall and O. D. Adeuyi, "CM Project Overview”, Grid Code Project Kick-off Meeting National HVDC Centre, May 2019

[6] National Grid, "The System Operability Framework", July 2018

[7] National Grid, "Future Energy Scenarios", July 2018.

[8] Commission Regulation (EU) 2016/1447 of 26 August 2016 establishing a network code on requirements for grid connection of high voltage direct current systems and direct current-connected power park modules (Text with EEA relevance).

[9] National Grid, "The Grid Code", Issue 5, revision 36, July 2019.

[10] National Grid ESO, "Stability Pathfinder RFI Technical Performance and Assessment Criteria".

[11] R. Teixeira Pinto, S. F. Rodrigues, P. Bauer and J. Pierik, "Grid code compliance of VSC-HVDC in offshore multi-terminal DC networks, in IECON 2013 - 39th Annual Conference of the IEEE Industrial Electronics Society, Vienna, 2013, pp. 2057-2062.

[12] O. A. Giddani, G. P. Adam, O. Anaya-Lara, G. Burt and K. L. Lo, "Control strategies of VSC-HVDC transmission system for wind power integration to meet GB grid code requirements," in SPEEDAM 2010, Pisa, 2010, pp. 385-390.

[13] M. Ndreko, A. Bucurenciu, M. Popov and M. A. M. M. van der Meijden, "On grid code compliance of offshore mtdc grids: modeling and analysis," in 2015 IEEE Eindhoven PowerTech, 2015, pp. 1-6.

[14] "Beyond state-of-the-art technologies for power AC corridors and multi-terminal HVDC systems (Best Paths)", EU Project nr. 612748.

[15] E. Ciapessoni et al., "Assessing the impact of multi-terminal HVDC grids for wind integration on future scenarios of a real-world AC power system using grid code compliant open models," in 2017 IEEE Manchester PowerTech, Manchester, 2017, pp. 1-6.

[16] C. E. Ugalde-Loo et al., "Open access simulation toolbox for the grid connection of offshore wind farms using multi-terminal HVDC networks," in 13th IET International Conference on AC and DC Power Transmission (ACDC 2017), Manchester, 2017, pp. 1-6.

[17] O. D. Adeuyi, M. Cheah-Mane, J. Liang and N. Jenkins, "Fast Frequency Response From Offshore Multiterminal VSC-HVDC Schemes," IEEE Trans. Power Del., vol. 32, no. 6, Dec. 2017.

[18] K. Jose, T. Joseph, J. Liang, and C. E. Ugalde-Loo, "Auxiliary deadband controller for the coordination of fast frequency support from multi-terminal HVDC grids and offshore wind farms," IET Renewable Power Generation, vol. 12, no. 13, 1444-1452, Oct. 2018.

[19] T. Joseph, C. E. Ugalde-Loo, S. Balasubramaniam and J. Liang, "RealTime Estimation and Damping of SSR in a VSC-HVDC Connected Series-Compensated System," IEEE Trans. Power Syst., vol. 33, no. 6, pp. 7052-7063, Nov. 2018.

[20] T. Joseph, C. E. Ugalde Loo, S. Balasubramaniam, J. Liang and G. Li, "Experimental Validation of an Active Wideband SSR Damping Scheme for Series-Compensated Networks," IEEE Trans. Power Del., vol. 35 , no. 1 , pp. $58-70$, Feb. 2020.

[21] P. Kundur, Power System Stability and Control, McGraw Hill, 1994

[22] N. R. Chaudhuri, "Integrating Wind Energy to Weak Power Grids using High Voltage Direct Current Technology", Springer International Publishing, April 2019.

[23] IEEE Guide for Planning DC Links Terminating at AC Locations Having Low Short-Circuit Capacities," IEEE Std. 1204-1997, pp. 1216, 21 Jan. 1997

[24] J. Z. Zhou, H. Ding, S. Fan, Y. Zhang, and A. M. Gole, "Impact of short-circuit ratio and phase-locked-loop parameters on the small-signal behavior of a VSC-HVDC converter," IEEE Trans. Power Del., vol. 29, no. 5, pp. 2287-2296, Oct. 2014.

[25] R. Tumilty, "Caithness - Moray HVDC System Integration," CM Stake holder engagement event, National HVDC Centre, Glasgow 2019.

[26] Strathclyde Engagement with the UK National HVDC Centre: Phase I Converter and GB Network Modelling, "Offline DC grid model development”, Doc. No. USTRATH-HVDC Centre-P1-003, 2018. 